\title{
COOPERACIÓN INTERNACIONAL Y CONSTRUCCIÓN DE PAZ: MIRADAS HISTÓRICAS Y REFLEXIVAS SOBRE COLOMBIA
}

\author{
INTERNATIONAL COOPERATION AND PEACEBUILDING: HISTORICAL AND \\ REFLECTIVE VIEWS ON COLOMBIA
}

COOPERAÇÃO INTERNACIONAL E CONSTRUÇÃO DA PAZ: VISÕES HISTÓRICAS E REFLEXIVAS SOBRE A COLÔMBIA

Juan David Abella Osorio Cocoordinador de Estudios de Asia e Investigador internacional, Programa de Investigación de Política Exterior Colombiana (PIPEC), Universidad de los Andes, Colombia jd.abella@uniandes.edu.co| https://orcid.org/oooo-00o2-4425-8914

Sugerencia de citación: Abella Osorio, J. D. (2022). Cooperación internacional y construcción de paz: miradas históricas

Fecha de recepción: 15 de septiembre de 2021 Fecha de aceptación: 30 de noviembre de 2021 Disponible en línea: 30 de diciembre de 2021 y reflexivas sobre Colombia. Razón Crítica, 12. https://doi.org/10.21789/25007807.1811

\section{Resumen}

En el ámbito del estudio y la práctica de la guerra y la paz, Colombia es sin duda un caso disruptivo e interesante de estudio. Por un lado, es un hecho que el país ha experimentado uno de los conflictos armados más longevos de la región y del mundo, que además ha demostrado una altísima adaptabilidad y complejidad, que se entremezcla con la ya delicada situación social y política del país. Por otro lado, Colombia también lleva más de diez años buscando una solución negociada al conflicto, al tiempo que ha adelantado numerosas medidas de verdad, justicia y reparación para las víctimas, en una escala y ambición solo comparable con los esfuerzos realizados para atender a las personas desplazadas en Europa tras la Segunda Guerra Mundial. Dicho esto, el presente artículo se propone estudiar la relación histórica y actual de la cooperación internacional y construcción de paz, proponiendo y desarrollando para este fin un nuevo modelo de comprensión que pretende facilitar el entendimiento de ambos fenómenos, y contribuir al entendimiento de los vínculos históricos entre ambas dinámicas, ofreciendo al tiempo un marco útil en favor de análisis prospectivos relevantes en la materia.

Palabras clave: conflicto armado; construcción de paz; cooperación internacional; sistema internacional. 


\begin{abstract}
In the field of the study and practice of war and peace, Colombia is undoubtedly a disruptive and interesting case of study. On the one hand, the country has experienced one of the longest-lived armed conflicts in the region and in the world and has also shown a high degree of adaptability and complexity, which is intermingled with the already delicate social and political situation of the country. On the other hand, Colombia has also been seeking a negotiated solution to the conflict for more than ten years at the same time that it has implemented numerous measures of truth, justice, and reparation for the victims, on a scale and ambition only comparable to the efforts made to attend displaced people in Europe after the Second World War. That said, this article aims to study the historical and current relationship of international cooperation and peacebuilding, proposing and developing for this purpose a new understanding model that serves to facilitate the comprehension of both phenomena, and contribute to the consideration of the historical links between both dynamics, offering at the same time a useful framework in favor of relevant prospective analyzes on the matter..
\end{abstract}

Keywords: armed conflict, peacebuilding, international cooperation, international system.

\title{
Resumo
}

No contexto deste estudo e da prática da guerra e da paz, a Colômbia é, sem dúvidas, um caso disruptivo e relevante de estudo. Por um lado, é fato que o país vem experimentando um dos conflitos armados mais longínquos da região e do mundo, que, além disso, vem demonstrando uma altíssima adaptabilidade e complexidade, que se fusionam com a já delicada situação social e política do país. Por outro lado, na Colômbia, há mais de dez anos se busca uma solução negociada para o conflito, ao mesmo tempo que vem realizando inúmeras medidas de verdade, justiça e reparação para as vítimas, numa escala e ambição somente comparáveis com os esforços feitos para atender as pessoas deslocadas na Europa após a Segunda Guerra Mundial. A partir disso, neste artigo, propõe-se estudar a relação histórica e atual da cooperação internacional e da construção da paz, apresentando e desenvolvendo para isso um novo modelo de compreensão que pretende facilitar o entendimento de ambos os fenômenos, e contribuir para o entendimento dos vínculos históricos entre essas dinâmicas, oferecendo paralelamente um referencial útil a favor de análises prospectivas relevantes na matéria.

Palavras-chave: conflito armado; construção da paz; cooperação internacional; sistema internacional.

Colombia ha sufrido por más de 50 años del conflicto armado más prolongado del hemisferio occidental, que ha sido heterogéneo tanto en el tiempo como en el territorio, así como en sus protagonistas, sus víctimas y sus manifestaciones de violencia. La gran multiplicidad de actores e intereses, las profundas ambiciones políticas, las permanentes tensiones sociales y económicas, junto con la lucha histórica por el control de los recursos, han generado más de 7 millones de víctimas, lo que equivale al 13 \% de la población del país. Se ha configurado así el mayor drama humanitario de la historia de América Latina (Rolón Salazar, 2018).

En términos generales, hasta el 2012 este conflicto armado le ha costado al país más de 207 billones COP, la misma cantidad de recursos que se necesitarían para construir 5,3 millones de viviendas, cientos de kilómetros en sistemas de transporte terrestre, además de un megacolegio y un megahospital en cada uno de los 1.120 municipios de Colombia (Monroy, 2012). De hecho, de acuerdo con estudios del Centro de Recursos para el Análisis de Conflicto (Cerac), con una reducción del conflicto armado en un $100 \%$, y si todas las demás variables de 
contexto permanecieran constantes, aumentaría el PIB departamental en un 4,4 \% anualmente, en promedio (Villa et al., 2013).

A pesar de este oscuro escenario, Colombia lleva también más de 10 años aplicando medidas para desmovilizar combatientes y conseguir verdad, justicia y reparación para las víctimas en el marco de una búsqueda permanente por la solución negociada al conflicto armado. Esta se ha desarrollado a través de fases sucesivas de negociación política con grupos guerrilleros y paramilitares a lo largo de las últimas tres décadas, lo que ha venido adicionando piezas (leyes y políticas) a la estrategia nacional de justicia transicional, la cual aún sigue formándose y está en constante evolución para dar respuesta a los desafíos de un conflicto heterogéneo y complejo como el colombiano.

Ahora bien, el desafío de Colombia en materia de atención y reparación integral a las víctimas del conflicto es enorme y así ha sido asumido por el Estado al proponer y comenzar a implementar el modelo de atención más ambicioso del mundo, solo comparable en escala con los esfuerzos realizados para atender a las personas desplazadas en Europa tras la Segunda Guerra Mundial.

De acuerdo con el informe elaborado por la Universidad de Harvard sobre las verdaderas posibilidades que tiene el Estado de cumplir con los propósitos que se trazó, se pone en evidencia que los objetivos de Colombia de reparar a más del $14 \%$ de la población actual del país podrían superar las capacidades de la Unidad para las Víctimas y sobrepasar los límites presupuestales proyectados por el Estado, lo que obligaría a extender los plazos y buscar nuevas fuentes y apoyos adicionales, principalmente en el exterior (Sikkink et al., 2014).

Dicho esto, una reflexión acerca de las dinámicas e intervención de la cooperación internacional en la construcción de paz en Colombia, entendiendo ambos como fenómenos históricos, transversales y dinámicos en la historia nacional, resulta especialmente pertinente debido a sus estrechos vínculos funcionales y complementarios.

Para conseguir esto se propone no solo una reflexión desde el contexto de la cooperación, también se pretende analizar las transformaciones y adaptaciones de las dinámicas de ayuda y relación externa del país con el sistema internacional, a la luz de los cambios y demandas internos, generados especialmente a raíz de la ocurrencia y manejo de los fenómenos de subdesarrollo, conflicto y negociación política. Esto resulta especialmente pertinente con el fin de comprender una de las múltiples variables vinculadas con el devenir de los sucesos políticos domésticos y exteriores de Colombia. Para lograr este análisis, la presente sección propone una exploración articulada y analítica distribuida en las siguientes secciones.

En la primera sección se desarrollará una mirada descriptiva a la evolución de la cooperación internacional en Colombia frente al fenómeno de la construcción de paz, destacando los principales hitos en dicho devenir histórico en el marco de las agendas no solo de seguridad, sino también de ayuda humanitaria, fortalecimiento institucional, reconocimiento y reparación para las víctimas, y desarrollo. En esta tarea se tendrá en cuenta no solo la evolución de la cooperación internacional (CI) en los ámbitos institucional y social, 
también se dará una especial atención a las conexiones entre los sucesos en el ámbito del sistema internacional, y los acontecimientos que marcaron la vida política y económica del país. Al final, se pretende revelar una fotografía con la mayor amplitud posible con el objetivo no solo de introducir al lector a la temática, también para facilitar una lectura reflexiva y crítica de las secciones subsiguientes.

En la segunda sección se expondrá y explicará el marco teórico-conceptual que será tenido en cuenta, con el fin de explorar el siempre complejo fenómeno y noción de “cooperación internacional" (CI). Al respecto, y para fines del presente estudio, se ofrecerá una propuesta de modelo de comprensión entre la ci y la construcción de paz, la cual busca, además de facilitar el entendimiento de ambos fenómenos, contribuir al entendimiento de los vínculos históricos entre ambas dinámicas, ofreciendo al tiempo un marco útil en favor de análisis prospectivos relevantes en la materia.

Teniendo en cuenta las posibilidades permitidas por el modelo conceptual propuesto, sumado al contexto histórico explicado en la primera sección, el tercer aparte busca desarrollar una reflexión analítica y sistémica a la relación compleja existente entre los fenómenos de cI y construcción de paz en Colombia, comprendiendo transversalmente que se trata especialmente de un vínculo de interdependencia, en el cual las ideas y discursos políticos juegan un papel central a la hora de fijar los alcances y limitaciones correspondientes.

Finalmente, se presentarán las principales conclusiones extraíbles de la reflexión propuesta. En este aparte se pretende sintetizar los hallazgos de la reflexión descriptiva y analítica propuesta, revelando las conexiones y vínculos entre las distintas secciones del documento con base en el modelo conceptual propuesto, dando una especial atención al estudio de la interdependencia de los fenómenos de cI y construcción de paz en Colombia, involucrando en el estudio el manejo de cuestiones tales como el subdesarrollo, el conflicto y negociación política.

\section{Contexto: una mirada a la evolución de la cooperación internacional en Colombia}

Entender el origen y transformación de la CI como concepto y fenómeno implica comprender el entrelazamiento de dos dimensiones. La primera consiste en su dimensión histórica, esto es, la revisión de la serie de hechos y sucesos históricos que, convergentemente, forjaron unas condiciones para el surgimiento de la CI. La segunda dimensión corresponde a las reflexiones y avances teóricos y analíticos, los cuales se desarrollaron especialmente (pero no exclusivamente) a partir de las teorías económicas desarrollistas y de dependencia. La confluencia de estos rasgos ha permitido la gestación del llamado "sistema de cooperación internacional para el desarrollo” (Duarte \& González, 2014; Sanahuja, 2001)

Un hito que marca especialmente el surgimiento y los destinos de la CI como fenómeno fue el escenario de destrucción y miseria ocasionado gracias a la Segunda Guerra Mundial (1939-1945). Estas condiciones, sumadas a la convergencia de otras variables histórico- 
políticas excepcionales, posibilitaron la aparición y nacimiento de una conciencia global expresada en el reconocimiento, la necesidad y la relevancia de realizar la cooperación internacional como una alternativa y herramienta fundamental con el fin de mantener la paz, prevenir futuros conflictos genocidas, y sostener la y resquebrajada seguridad internacional tan vulnerada en los años de guerra (Duarte \& González, 2014).

Precisamente, las circunstancias de posguerra hicieron que las políticas de ayuda externa y la cooperación internacional se dirigieran a la reconstrucción de las condiciones de vida y de producción, haciendo de ello los elementos fundantes y constitutivos del sistema internacional de posguerra e incluso su rasgo histórico singular. Previamente al contexto sufrido por la comunidad internacional en 1945, las políticas de ayuda no existían como tales, sino que fueron gestadas como respuesta frente a las aceleradas transformaciones que ha experimentado dicho sistema (Duarte \& González, 2014; Calabuig \& Gómez-Torres, 2010).

El carácter altamente dinámico del sistema internacional, anclado estrechamente a la recomposición de las estructuras de poder en el mundo, ha generado igualmente que la valoración y participación internacional directa e indirecta en los procesos de paz alrededor del globo esté en constante cambio. Precisamente, el colapso de la llamada "Guerra Fría" reveló cambios sustanciales en las relaciones e interacciones al interior del sistema internacional, tanto en la estructura de poder global como en el nuevo protagonismo de los organismos multilaterales y las agencias de cooperación. Las últimas se enfrentaron a un nuevo escenario de actividad al dejar de ser el espacio de disputa entre las dos grandes potencias mundiales (Colmenares, 2006).

De hecho, con el retiro de las grandes potencias de sus áreas tradicionales de influencia y de concordia, la población civil ha emergido con mayor visibilidad como uno de los principales ejes de los conflictos armados, con un incremento marcado del número y las dimensiones de las crisis humanitarias. La suspensión del apoyo de las potencias en materia de recursos militares y financieros ha dejado a los grupos armados ante la necesidad de buscar sus propios medios a su alcance, evolucionando hasta convertirse en genuinas estructuras depredadoras y criminales que violentan los recursos naturales, además de los bienes y derechos de la población, con el fin de garantizar su continuidad en los conflictos internos y regionales.

Paradójicamente, y siguiendo a Colmenares (2006), los hechos ocurridos el 11 de septiembre del 2011 no solo transformaron significativamente la política exterior de Estados Unidos, lo que robustece su llamada "Guerra Global al Terrorismo", también atrajeron la atención en los conflictos armados prolongados y los Estados fallidos existentes en el contexto internacional, vistos como focos y catalizadores de la amenaza terrorista. Así, de manera histórica y global, conflictos como el colombiano ya no serían vistos más como simples guerras periféricas llevadas a cabo por insurgencias armadas; por el contrario, pasarían a convertirse en una pieza clave del nuevo panorama de enfrentamiento global (Colmenares, 2006).

Las constantes evoluciones en la política en el sistema internacional favorecen la formación de nuevos constructos y énfasis sobre el desarrollo, entre los cuales se destacan 
especialmente los conceptos de "seguridad humana" y "desarrollo humano", que introducen la relevancia de iniciativas paralelas, o alternativas, al conflicto consistentes en apoyar programas de las sociedades civiles de carácter transversal, esto es, de actividades orientadas tanto hacia el posconflicto como para los tiempos paralelos a la evolución del conflicto.

Un hito de especial atención para la relación entre construcción de paz y cooperación internacional surge en 1992 con el marco de la Agenda para la Paz del Secretario General de Naciones Unidas, una iniciativa que reflejaba la preocupación y el optimismo sobre el papel que debería jugar el sistema de Naciones Unidas en la gestión de los conflictos y la paz internacional, y que además se complementaba orgánicamente con otro documento trascendental para la época, la Agenda para el Desarrollo.

Está visión optimista y esperanzadora se vio entorpecida luego de los fracasos en los procesos de paz en Somalia, Ruanda, Zaire, Angola y Bosnia, los cuales dejaron en entredicho la efectividad real de la ONU a la hora de intervenir positivamente en los conflictos armados. Como consecuencia de estas experiencias difíciles, las perspectivas y la naturaleza de la participación de la comunidad en las crisis políticas y armadas sufren distintas transformaciones y ajustes.

$\mathrm{Al}$ respecto, las políticas de intervención para la paz de la ONU cambian gradualmente desde su concentración en las "transiciones" hacia una función más de garante, de actor activo tanto en las fases de negociación como en las etapas propias del posconflicto, integrando iniciativas de desarrollo local y comunitario. Un buen ejemplo de esto último se encuentra en el caso salvadoreño, donde los aportes de ONU desde comienzos del acercamiento fueron claves para el subsiguiente éxito del proceso de negociación.

La evolución y los cambios en la agenda de prioridades de la comunidad internacional han alcanzado un punto de desarrollo que hoy día permite una variedad de oportunidades para que la ONU y otros organismos multilaterales desempeñen un papel cada vez más complejo y relevante en los procesos de prevención y solución de los conflictos violentos en el mundo.

La cooperación en Colombia empezó en los años cincuenta, gracias a la firma de convenios entre el Banco Interamericano de Reconstrucción y Fomento (BIRF), la Organización de Estados Americanos (OEA), los Estados Unidos, el Consejo Nacional de Política Económica y Social (Conpes), y el Departamento Nacional de Planeación (DNP) ${ }^{1}$. En 1954, Colombia firmó un convenio con la ONU cuyo fin consistía en "favorecer el progreso económico y social y el desarrollo de los pueblos" (Gutiérrez, 2012).

Posteriormente, se determinó que la cuestión de la cooperación internacional debía ser una de las funciones del Ministerio de Relaciones Exteriores, puesto que no solo era la cartera más especializada en materia de relaciones internacionales, también por su experiencia en el

1 Específicamente, la labor de relacionamiento con los socios y demás actores internacionales se hacía por medio de la Unidad de Proyectos Especiales y Crédito Externo, que como función principal dirigía y manejaba los

financiamientos provenientes del exterior 
relacionamiento del país con otros actores del sistema internacional. Para facilitar esta asignación, se conformó en aquel instante la Dirección de Cooperación Internacional del Viceministerio de Asuntos Multilaterales.

Con la conversión de la División Especial de Cooperación Técnica Internacional al interior del DNP en una Agencia Colombiana de Cooperación Internacional (ACCI), se iniciaba la diferenciación de funciones entre las distintas oficinas llamadas a coordinar la cooperación internacional. Frente al cambiante escenario internacional y la evolución de la agenda global, los ajustes institucionales como los mencionados se explican sobre todo como una respuesta para aprovechar el direccionamiento de los esfuerzos externos en favor de los países en desarrollo.

La nueva institucionalidad también pretendía la consecución de iniciativas de cooperación técnica con el fin de suplir necesidades comunes de orden horizontal inaugurándose así la cooperación técnica entre países en desarrollo (CTPD). Precisamente, de manera paralela con el surgimiento de la ACCI, se expide en aquel entonces un segundo documento Conpes, titulado "Nuevo enfoque de la cooperación internacional", en el cual se proponen "políticas para revertir la tendencia decreciente de recursos, consolidar la cooperación como instrumento de apoyo al desarrollo y asegurar la entrada en operaciones de la nueva agencia" (Gutiérrez, 2012).

Durante el gobierno de Andrés Pastrana (1998-2002) se produce un cambio al pasar la ACCI hacia el Ministerio de Relaciones Exteriores, revelándose ahora como instrumento para la policía exterior, que sería empleado a fondo en la ambiciosa actividad diplomática del Gobierno. Esta diplomacia pretendía obtener tanto apoyo político como económico para la búsqueda de la paz y la salida negociada con los grupos ilegales internos. En pocas palabras, se concebía a la cooperación internacional como un medio básico de la política exterior, guiada por una estrategia superior, denominada "diplomacia para la paz" (Martínez et al., 2008).

La laboriosa actividad exterior del Gobierno y su diplomacia para la paz resultó en el llamado "plan Colombia", una estrategia integral diseñada para conseguir la consolidación de condiciones de reconciliación, paz y desarrollo social en el país, en el mediano y largo plazo. El plan Colombia se construyó con base en los siguientes cuatro componentes interrelacionados: i) proceso de negociación política del conflicto armado; ii) lucha antinarcóticos; iii) recuperación y reconstrucción económica y social, y iv) fortalecimiento institucional y desarrollo social. Para desarrollar este cuarto elemento, el Gobierno decidió contar con la asesoría técnica del BID, en el marco del Grupo de Apoyo al Proceso de Paz, que se reunió sucesivamente en las denominadas mesas de aportantes realizadas en Madrid (2000), Bogotá (2000), y Bruselas (2001) (Martínez et al., 2008).

En síntesis, la estrategia durante este periodo pretendía la máxima participación de la comunidad internacional en la negociación política con los grupos armados, incluyendo incluso el concurso de las guerrillas en la búsqueda de recursos y apoyo externo. En este caso, y bajo una fuerte centralización, se apunta como socio estratégico a Estados Unidos, y se robustece el vínculo de la paz con el problema del narcotráfico. Igualmente, se procuró la consecución de 
recursos masivos en el exterior que permitieran reforzar la ofensiva contra las bases sociales y económicas que posibilitaban el desarrollo de los narcocultivos.

A pesar de los éxitos en la obtención de apoyo político y económico externo, sumado a la formalización de las simpatías a favor de la cuestión de la paz de Colombia en América Latina y Europa, la situación del país durante este periodo lo hizo ser percibido más como una amenaza regional (e incluso internacional). Dicho esto, mientras que el conocimiento o visibilidad de Colombia (en el contexto hemisférico) estuvo más vinculado a su crisis interna y externa, esta cuestión no parecía estar en la agenda de las élites de manera completamente consciente.

Al respecto, según Tokatlian (1999), estas élites aún percibían a Colombia como aquel país de los sesenta y ochenta. Este estaría caracterizado por ser un reconocido aliado de Estados Unidos, un referente en la lucha antinarcóticos y un símbolo de la democracia para sus vecinos. Esto ocurría justo cuando sus índices de corrupción y violación de los derechos humanos eran inferiores a los promedios del hemisferio.

Con la llegada del 2000 las cuestiones de cooperación internacional y construcción de paz en Colombia no trajeron desafíos menos complejos. Para muchos de sus pares inmediatos y distantes en la región, el país exportaba inseguridad e ingobernabilidad, y era un eventual peligro para la estabilidad general. No era para menos, puesto que el panorama factual era apreciado como dramático en el contexto internacional: "[...] desplazados, paramilitares y guerrilleros colombianos en Panamá, insurgentes y narcotraficantes nacionales cruzando la frontera con Venezuela, utilización del territorio ecuatoriano y peruano como santuario temporal para la insurgencia armada y espacio de expansión del paramilitarismo y el narcotráfico" (Tokatlian, 1999, p. 358).

Sin duda, bajo el contexto anterior, es posible sostener que los vínculos entre cooperación internacional y construcción de paz resultaban altamente complejos, encontrándose a mitad de camino entre las ambiciones y apuestas de paz del Gobierno, el protagonismo de las guerrillas y las preocupaciones persistentes sobre el caso y el destino del conflicto colombiano, el cual era visto con preocupación y con sentido de urgencia desde Canadá hasta Argentina. Como será analizado más adelante, una retórica y actuación externa similar a la diplomacia por la paz, nunca ha podido intensificarse si en el ámbito nacional no se producen avances, cambios y compromisos genuinos para lograr la resolución pacífica de la guerra.

Desde el 2002 el Estado buscó ir más allá del enfoque tradicional de la cooperación, haciéndola extensiva hacia otros sectores de la sociedad (distintas a las de la gestión gubernamental propiamente), favoreciendo al mismo tiempo la obtención de nuevos medios y recursos de cooperación con base en fuentes que no habían sido explorados son suficiente atención. Una interesante referencia a este cambio y estas metas se encuentra precisamente en la presentación de la estrategia de cooperación internacional, que reflejó en aquel entonces un esfuerzo concertado de apropiación de las necesidades y expectativas frente a la ayuda externa (Martínez et al., 2008). 
Al mismo tiempo, se registraron importantes avances en el sistema nacional de cooperación internacional (SNCI), el cual se diseñó para constituir un espacio que facilitara la articulación de la gestión de la cooperación técnica y los entes subnacionales. En este periodo también ocurre la adhesión de Colombia la Declaración de París (DP), un instrumento que establece como prioridad la oferta de ayuda eficiente, avanzando con base en los siguientes principios: i) aumentar la eficacia de la ayuda al desarrollo; ii) adaptar las políticas a la situación y demandas específicas de cada país; iii) especificar indicadores, calendarios y metas, con base en una agenda programática de largo plazo, y iv) posibilidad de monitorear y evaluar la realización de las actividades de cooperación (Gutiérrez, 2012).

Ahora bien, en propiedad, la estrategia colombiana en materia de cooperación empezó en junio del 2003 con la Reunión de Londres, un escenario que reunió en un mismo espacio a las principales fuentes cooperantes y a actores de la sociedad civil, y que el Gobierno nacional aprovechó para presentar el documento "Una coalición internacional por la paz de Colombia", que sentó las bases para la elaboración de la propuesta de estrategia. Como primera fase de este proceso, se realizaron distintas acciones tendientes a organizar y priorizar la demanda de cooperación con el concurso de distintas entidades nacionales, y además se generaron espacios de diálogo y concertación con la sociedad civil y con las fuentes cooperantes.

Otro suceso relevante en este periodo fue el cambio institucional que representó la fusión de la ACCI con la Red de Solidaridad Social, lo cual propició la constitución de la Agencia Presidencial para la Acción Social y la Cooperación Internacional (Acción Social), creada por el decreto 2467 del 19 de julio del 2005. No obstante, anteriormente ya se habían producido otros ajustes organizacionales por medio de la adscripción de la anterior ACCI al Departamento Administrativo de la Presidencia de la República (Dapre), mediante el decreto 1540 de junio 6 del 2003, lo cual marcó el énfasis ejecutivo, centralizado y gerencial que el gobierno de Álvaro Uribe quería dar a la gestión de la cooperación internacional (Martínez et al., 2008).

En el 2005, el Gobierno emprendió en Cartagena la Segunda Mesa de Coordinación y Cooperación Internacional para Colombia, la cual contó con la intervención de los máximos representantes de los países miembros del G24, además de altos dignatarios mundiales. Aprovechando la coyuntura favorable de atención internacional en el país, el Gobierno presentó a sus socios reales y potenciales el documento "Estrategia de Cooperación Internacional” del Gobierno de Colombia, y el Informe de seguimiento a las recomendaciones de Naciones Unidas en materia de derechos humanos.

También en el 2005, y como parte de los esfuerzos de concertación descritos, se conformó una Comisión de Seguimiento para los temas de Cooperación Internacional, compuesta colegiadamente por parte de Acción Social, la Cancillería, la Vicepresidencia y el DNP (por parte del Gobierno), junto con la troika más tres embajadas del G24 $4^{[2]}$, algunos cooperantes, y varios actores de sociedad civil. Este mecanismo, de carácter permanente, se

\footnotetext{
${ }^{2}$ Grupo informal de coordinación de donantes, que facilitó la interlocución periódica y constructiva entre las fuentes cooperantes y las autoridades nacionales, y entre ellos y diversos representantes de la sociedad civil.
} 
encargó de realizar el seguimiento necesario a los avances en la concreción de nuevos aportes frente a la estrategia propuesta por el Gobierno (Martínez et al., 2008).

Los avances no fueron solo en materia de coordinación o en el ámbito institucional. Con el tiempo y gracias a la mayor intensidad en la comunicación entre agentes, el Estado consideró que era necesario aumentar la integración entre la cooperación internacional y las prioridades sociales del país, teniendo en cuenta, además, que el presidente, como rector de la política exterior del país, establece los lineamientos y las prioridades en la materia. Ahora bien, a pesar de la evidente centralización de la visión y disposición de la cooperación, siempre se ha mantenido una coordinación con el Ministerio de Relaciones Exteriores, la cual mantenía los deberes de diseñar, estudiar y fijar la política exterior y de cooperación internacional.

Otro avance destacado consistió en la exploración de fuentes y esquemas alternos de cooperación, esto es, el interés manifiesto del Gobierno para trabajar a partir de modalidades no tradicionales de cooperación. Este interés, que se mantendría en distintos niveles a lo largo del tiempo, es también un reconocimiento implícito del papel que cumplen las ONG como gestoras de la ayuda externa disponible. Así, con la creación de Acción Social, aparece la Subdirección de Nuevas Fuentes de Cooperación Internacional, instancia que sería encargada de identificar fuentes cooperantes no oficiales, en las modalidades descentralizada, privada, de organizaciones religiosas, gremios, empresas, fundaciones empresariales y ONG, así como debía contactarlas y promover la generación de alianzas con entidades nacionales para la obtención de recursos de cooperación nacional e internacional (Martínez et al., 2008).

Solo sería hasta la Tercera Conferencia Internacional para Colombia, realizada en Bogotá en el 2007, cuando la versión final de la Estrategia de Cooperación Internacional para el periodo 2002-2010 estuvo lista para su exposición y entrega correspondiente. $\mathrm{Al}$ respecto, la Tercera Conferencia marcó el compromiso de los cooperantes de Colombia en "[...] seguir cooperando en un espíritu positivo y constructivo, proporcionando los recursos necesarios para financiar los programas de cooperación conjuntamente identificados y adoptados”. Paralelamente, se encargó el diseño e implementación de múltiples herramientas y publicaciones encaminadas a mejorar la gestión, el seguimiento y evaluación de la cooperación, tales como mapas temáticos, ilustraciones, manuales, concursos de investigación y los cursos virtuales sobre gestión de proyectos de cooperación.

Como consecuencia de este y los procesos previos de concertación, y gracias a una renovación en los ánimos de colaboración, se registraron algunos resultados positivos: i) aumento de los flujos de la ayuda oficial al desarrollo, que pasaron de 150 millones usD en el 2001 a 394 millones en el 2007; ii) generación de escenarios de coordinación y articulación que derivaron en la constitución del G24; iii) incremento en la oferta de cooperación horizontal colombiana hacia América Latina, mejorando el posicionamiento estratégico del país como oferente de cooperación internacional o como donante emergente (en el marco de la cooperación técnica entre países en desarrollo - CTPD-); y iv) aumento de actividades de CTPD, que pasó de 71 (por valor de 294 millones USD) a 131 por el valor de $\$ 1.178$ millones USD (Martínez et al., 2008). 
La afiliación de Colombia a la DP en el 2007 fue un logro sobresaliente, en razón a que esta adscripción podría mejorar la coordinación y efectividad de la cooperación en Colombia, e implicaría adoptar arreglos y ajustes de parte de los cooperantes y del país en la definición y ejecución de la ayuda externa. Esto se hizo con el objetivo último de cumplir las metas allí previstas en los temas de alineación, armonización, apropiación, gestión orientada a resultados y mutua responsabilidad.

Así mismo, luego de esta adhesión, Colombia se ha caracterizado por ejercer un perfil de liderazgo en el ámbito externo, con lo cual obtuvo los siguientes resultados: i) fue designada junto con Suiza como copresidente de la Mesa de Apropiación del Foro de Alto Nivel Sobre Eficacia de la Ayuda, realizada por la OCDE en Accra; ii) hizo parte del Grupo de Trabajo sobre Efectividad de la Ayuda y del Grupo Asesor sobre Sociedad Civil y la Efectividad de la Ayuda, y iii) consiguió ser la sede de la Consulta Regional de América Latina y el Caribe, realizada en Santa Marta en junio del 2008, como preparación para el III Foro de Alto Nivel, y lideró el Foro Virtual sobre Apropiación, apoyado por la OCDE.

Desde el 2009, la cooperación y su vínculo con la construcción de paz sufrió nuevamente una serie de cambios sobresalientes. En primer lugar, ocurrió la Misión de Política Exterior llevada a cabo entre el 2009 y el 2010 por Borda y Bell, Gómez, Ramírez, Reina, Reyes y Tokatlian. Con el interés en profesionalizar y tecnificar aún más la gestión exterior del Estado, el gobierno de Juan Manuel Santos tomó al pie de la letra las recomendaciones producidas por la Misión, emprendiendo acciones dirigidas a diversificar y ampliar el espectro de las relaciones internacionales del país, bajo la perspectiva de que un número mayor de alternativas de política exterior incidiría de manera directa en la facilidad con las que se obtendrían recursos y apoyo internacional para sus proyectos internos.

La profundización de los esquemas de cooperación sur-sur (CSS) fue precisamente una de las principales consecuencias de esa nueva política exterior, un comportamiento estatal consciente de que debía integrar al país a escenarios de influencia regional, multilateral y global, con el fin último no solo de cambiar la siempre difícil imagen internacional, sino también para fortalecer una posición creíble en las dinámicas de la cooperación internacional en calidad tanto receptor como de oferente de ayuda exterior de calidad (Pedraza \& Duarte, 2016).

Así mismo, algunos observadores políticos señalan que, en general, el periodo comprendido entre el 2009 y el 2018 se aprecia una orientación "réspice similia" (o incluso "réspice omnia") en la política exterior colombiana, pero sin pretender controvertir en temas estratégicos con Estados Unidos. En línea con este enfoque, fueron destacados los acercamientos a países del hemisferio como Perú, Chile y México, materializado en su máxima expresión con iniciativas como la Alianza del Pacífico (AP), constituida con un claro liderazgo y autonomía colombiana. $\mathrm{Al}$ respecto, a pesar de constituir una iniciativa de integración tan "reciente", la AP está pensada para ser el motor de la integración de América Latina, siendo ejemplares sus avances respecto a la eliminación de los requisitos de visas de turismo y negocios, así como la implementación de programas especiales para facilitar el intercambio cultural y académico para los ciudadanos de los cuatro países miembros (González et al., 2014). 
Igualmente, otra expresión de la orientación horizontal se vio en el papel activo de Colombia en la construcción de la agenda de los objetivos de desarrollo sustentable (ODS), los acercamientos por ingresar al foro APEC, el incremento en los flujos y actividades propias de la CSS,y el sorprendente protagonismo en cuestiones internacionales más delicadas como la campaña en favor del levantamiento del embargo comercial a Cuba por parte de Estados Unidos. Esto también incluye la actuación de Colombia en el Consejo de Seguridad de Naciones Unidas, elegida por séptima vez, y también en el campo bilateral, con la normalización de las relaciones con Venezuela y Ecuador (Fernández de Soto, 2012).

Otro elemento relevante fue el diseño de la Estrategia Nacional de Cooperación 20122014, el instrumento de direccionamiento que refleja, entre otras cosas, los principales objetivos estratégicos de la cooperación internacional en Colombia, fija las prioridades para organizar la demanda de ayuda exterior y consolida la oferta de cooperación del país, identificando las fortalezas y experticia que puede ofrecer Colombia a sus socios del mundo. Adicionalmente, presenta el esquema de coordinación de la cooperación internacional en Colombia y los mecanismos para su seguimiento y evaluación.

Ahora bien, la cuestión principal y transversal, con efectos catalizadores entre los vínculos entre cooperación internacional y construcción de paz en este periodo histórico, fue precisamente la negociación de paz en la Habana (2012-2016). Sin duda, esta negociación constituyó uno de los pilares de la política exterior vigente en cuanto el país, a través de la herramienta de la cooperación internacional para el desarrollo, ha solicitado apoyo y ayuda para finiquitar este conflicto a la sociedad internacional (Pedraza \& Duarte, 2016).

Dicho esto, se destaca que, aunque los socios tradicionales siguen aportando al país en esta nueva etapa, ya el protagonismo no se lo lleva únicamente Estados Unidos, gracias al incremento de la ayuda por parte de países que antes no lo hacían en un grado tan alto, como Canadá, Francia y Alemania (de hecho, este último ha aumentado la ayuda en un porcentaje significativo). Por ejemplo, estos países en cuatro años doblaron y hasta triplicaron lo que habían ayudado en los ocho años anteriores. Ahora bien, también se observan casos de reducción de la cooperación, como España o del mismo EE. UU. Mientras que en el caso español esto se explica en parte por la crisis económica del 2008, en el norteamericano se asocia con los cambios en la agenda de prioridades políticas internas y externas (Pedraza \& Duarte, 2016).

Bajo esta tendencia, se destaca igualmente los anuncios de parte de la UE en el 2016, comprometiéndose con un paquete cercano a los 600 millones EUR para la paz y el desarrollo de Colombia, lo cual incluye préstamos del Banco Europeo de Inversiones (BEI) por 400 millones EUR, así como subvenciones a través de un fondo fiduciario por un monto de casi 95 millones EUR. Según los anuncios, la prioridad de la destinación de estos dineros debe ser el apoyo a la implementación del acuerdo de paz con las FARC-EP, y la superación de los efectos negativos causados tras más de medio siglo de conflicto armado interno (Cerdà, 2016).

De las partidas iniciales valoradas por 95 millones EUR, 72 millones proceden directamente del presupuesto comunitario, 6 millones fueron otorgados por parte de España y 
Francia, y 3 millones fueron consignados por parte de Alemania y Reino Unido. De acuerdo a fuentes diplomáticas comunitarias, los socios europeos han señalado que el área fundamental de la inversión debía dirigirse al desarrollo rural y la financiación de la reforma agraria, entendiendo que el subdesarrollo y la inequidad en el campo causaron todos los movimientos revolucionarios en Colombia hace 50 años, tanto de las FARC como del ELN, la mala distribución de la riqueza y de la propiedad agraria. Hasta 2020, este fondo ha permitido apoyar más de 3.300 pequeñas y medianas empresas, 10 mil excombatientes han recibido formación en diferentes disciplinas y se han impulsado unos 9 mil proyectos colectivos que han beneficiado a más de 10 mil familias rurales (Banchón, 2020).

Luego, en el 2017, el Gobierno colombiano conformó el Fondo Colombia Sostenible (FCS), un instrumento que pretende gestionar una cifra prevista de 210 millones USD para los próximos tres años. El anuncio del FCS significa la protocolización del fondo que se había anunciado en diciembre de 2015 durante la COP 21 en París, que además forma parte del gran Fondo Colombia en Paz. Según datos del Gobierno, aunque la cifra de 210 millones usD sería el monto manejado en los primeros tres años, unos 100 millones provendrán de un préstamo convenido con el BID a Colombia, y los otros 110 provendrían de aportes internacionales. Específicamente, se esperaban ayudas, especialmente de países como Alemania, Noruega y Reino Unido, los cuales garantizarían su aporte con base en los resultados que se observen del proceso de posconflicto (Cerdà, 2016).

El gobierno de EE. UU. y el de Colombia anunciaron en febrero del 2016 la apertura de un nuevo capítulo del Plan Colombia, que se denominó Paz Colombia. El entonces presidente Barack Obama explicó que la ayuda de su país sería cercana a los 450 millones USD para el 2017, y que estos recursos serían invertidos para extender las oportunidades de construcción de paz por medio de la aplicación de la ley, especialmente en la garantía y protección de los derechos humanos (DD. HH.) y el respeto de los derechos de las víctimas (El Espectador, 2016). Los cuatro pilares para el manejo de los 450 millones USD para el Paz Colombia serían:

1. Lucha contra el crimen organizado: para que otras organizaciones no ocupen el vacío que dejarán las FARC en el mundo delincuencial. Este esfuerzo se ampliará a otros países de la región, donde se extienden las redes de estas bandas.

2. Apoyo al proceso de paz: un porcentaje de las ayudas será destinado a patrocinar la implementación de los aspectos logísticos y operativos de los acuerdos con las FARC, pactados en La Habana.

3. Desarrollo rural: se incluyen proyectos productivos y un impulso económico para llevar al Estado a esas zonas donde ha estado ausente, para llegar con colegios, hospitales y vías terciarias.

4. Erradicación de minas antipersonal: la meta es eliminar todas las minas de Colombia en cinco años a partir de ahora (Revista Semana, 2016).

Ahora bien, este monto y estos puntos estaban sujetos a la aprobación del presupuesto para el 2017 por parte del Congreso de Estados Unidos. Al final, el cuerpo legislativo validó una partida para el país de unos 391 millones USD, pero ratificó que los fondos debían destinarse específicamente a "implementar el acuerdo entre el Gobierno de Colombia y los grupos armados ilegales”, entre otros asuntos, así como a programas ya implementados, como los de antinarcóticos. Aunque esta decisión representó un incremento importante en los fondos para 
Colombia, el monto final no llegó a los 450 millones USD convenidos en un inicio por parte de la administración del expresidente Obama para el plan Paz Colombia (Armirola, 2017).

Otro suceso relevante en la evolución de la cooperación internacional y la construcción de paz constituye la formación, en abril del 2017, del Fondo Colombia en Paz (FCP). Este nuevo fondo estaba diseñado para recibir y administrar los recursos destinados para el posconflicto provenientes del presupuesto nacional, los aportes por motivo de regalías, el sector privado, y los apoyos venidos de la comunidad internacional. El Consejo Directivo del FCP está constituido por siete miembros, de los cuales cuatro son representantes independientes del sector privado. Este consejo tendrá la tarea de desempeñar el papel de eje central e instancia de coordinación de los esfuerzos institucionales y financieros dirigidos a apoyar a Colombia en su transición hacia el posconflicto (El Nuevo Siglo, 2017).

Adicionalmente, se destaca que este fondo agrupará los cuatro fondos ya operativos: el de la ONU, del Banco Mundial, de la Unión Europea y del BID. Sus recursos financiarán los distintos planes y proyectos específicos que lidere el Gobierno nacional, en múltiples áreas a las zonas afectadas por el conflicto armado en el país. Con el fin de garantizar el seguimiento y evaluación adecuada de todos los procesos contractuales de asignación de recursos, los socios han convenido promover la labor de los observatorios de transparencia ciudadana y el desarrollo de una auditoría realizada por una firma internacional. Así mismo, se plantea que todos los contratos se publicarían en el portal de Transparencia para la Paz para evitar la corrupción (Presidencia de la República de Colombia, 2017).

La evolución en la relación entre construcción de paz y cooperación internacional en los últimos años muestran los esfuerzos estatales por devolverle la institucionalidad a la diplomacia y la gestión de la oferta y demanda de la ayuda internacional. Ahora bien, aún restan tareas pendientes tendientes a recuperar la respetabilidad, dignidad del ejercicio diplomático y protagonismo de la cancillería en los asuntos exteriores, ya que aún se siguen presentando algunos lunares o salidas en falso (Pedraza \& Duarte, 2016).

\section{Aproximación teórica: propuestas de un modelo de comprensión entre la cooperación internacionall y la construcción de paz}

Los fenómenos de la cooperación internacional y la construcción de paz han sido abordados históricamente desde distintas direcciones. En el caso de la cooperación entre Estados y otros actores del sistema internacional, si bien los estudios conceptuales han sido dirigidos especialmente desde los grandes paradigmas de las relaciones internacionales, los aportes más profundos y concretos han venido, entre otras cosas, del paradigma liberal, específicamente del neoliberalismo institucional (Jiménez, 2003).

$\mathrm{Al}$ respecto, mientras que varios teóricos liberales advierten de la ocurrencia de una interdependencia política economía en el escenario internacional que genera, como consecuencia, una creciente demanda por cooperación entre los actores, algunos observadores de la escuela neoliberal como Robert Keohane advierten que las teorías liberales no solo dan 
por el hecho la existencia de intereses mutuos, también que la mayoría se dirigen a examinar las condiciones en las que estos intereses conducirán a la cooperación. De hecho, el mismo Keohane señala que la cooperación, además de ser la mejor manera de relacionarse, es quizá la única forma tanto para los Estados con economías de mercado avanzadas como para países menos desarrollados (Keohane, 1984).

Tanto la teoría del neoliberalismo institucional como las del neoinstitucionalismo y del constructivismo se destacan precisamente por sus contribuciones a la comprensión del desarrollo de la cooperación política entre Estados, en la medida que explican el papel de las instituciones en los flujos de intercambios en la escena internacional, analizando a su vez el contenido, las identidades y los intereses que quedan inmersos en dichos flujos (Jiménez, 2003). Dicho esto, no se deben subestimar los esfuerzos conceptuales en este sentido, más aún cuando desde estas orillas teóricas la cooperación se entiende como una mutua adaptación en la que preexisten intereses comunes y en la que se requiere de instituciones que reduzcan la incertidumbre y limiten las asimetrías de poder (Keohane, 1984).

Un elemento esencial en los estudios conceptuales de la cooperación corresponde a las instituciones internacionales, entendidas aquí como aquellos "conjuntos de reglas (formales e informales) persistentes y conectadas, que prescriben papeles de conducta, restringen la actividad y configuran las expectativas" (Keohane, 1984, p. 383). Estas instituciones son instrumentos de regulación que surgen como consecuencia de la creciente interdependencia entre los actores del sistema internacional, y tienen la meta de intervenir los desafíos y necesidades de coordinación y cooperación que implica la mencionada situación de interdependencia intensiva e histórica (Tickner, 1997).

Lo anterior sugiere que los fenómenos de cooperación entre actores del sistema internacional se ven ajustados usualmente a ciertos marcos limitantes, que encuadran lo que Keohane denomina "coordinación de políticas". Este concepto refiere a un proceso en el cual las acciones de individuos u organizaciones se adecúan por medio de una negociación en la que los actores adaptan sus conductas a las preferencias presentes o anticipadas de otros (Keohane, 1984). Sin ignorar las dificultades que enfrentan los diversos intentos de organizar mutuamente las políticas en ausencia de la hegemonía, el mensaje final de Keohane es que la cooperación no hegemónica es posible y que los regímenes internacionales la tornan más fácil.

En lo que respecta al fenómeno de la construcción de paz, su reflexión debe pasar inicialmente y obligatoriamente por una mirada a la cuestión de la noción de "paz". Como concepto, esta última constituye también una construcción humana que es, así como la idea de "guerra", una concepción tan antigua como la conciencia misma del ser humano de que vive en el seno de una sociedad (Dietrich, 2009).

Como consecuencia de la carga histórica del término, la idea de paz ha recibido múltiples interpretaciones. Al respecto, ha sido asociada a asuntos cotidianos y complejos como la naturaleza (desarrollado por las comunidades arcaicas con base en la relación con la madre tierra como fuente de alimentos), la divinidad (con los ritos de paz y fertilidad), la ética 
moral de la guerra, la construcción de contratos, o la misma institucionalización de la Iglesia y el Estado, entre muchas otras (Jiménez \& Aguilar, 2014).

Muñoz y López (2000) han señalado que la paz, entendida ampliamente como aquella regulación pacífica de los conflictos humanos, ha escalado hasta convertirse en una de las grandes preocupaciones del presente siglo. Se ha priorizado en la agenda de actores influyentes tales como políticos, religiosos, gentes de diversas culturas y estatus social, mujeres, jóvenes, empresarios, etc.

Este renovado interés, y el temor de fondo por las grandes catástrofes provocadas por los conflictos armados, ha derivado en la gestación de numerosas teorías (la mayoría interdisciplinarias). Entre estas se destacan los aportes de la llamada "investigación sobre la paz”. Esta última precisamente nació como resultado de los avances de las ciencias sociales durante los siglos XIX y XX, sumados al fuerte impacto emocional y moral generado por las dos grandes guerras mundiales, junto con los temores justificados ante una eventual primavera nuclear durante la guerra fría.

La investigación para la paz también ha conseguido visibilizar y extender los estudios en torno a tres formas de entender este concepto (paz negativa, positiva y neutra o cultural), de las cuales, y para fines del estudio actual, se tendrá en cuenta la paz positiva. Al respecto, la paz negativa establece la importancia de extirpar las fuentes de violencia directa, adoptando una concepción simplista que incluso tolera la apatía, dejando de lado la lucha activa por la paz y agregando nuevos problemas a los conflictos ya existentes. La paz neutra se dirige a combatir las variables culturales y simbólicas que legitiman el ejercicio de violencia directa. Por el contrario, la paz positiva apunta a una ausencia de violencia estructural o indirecta, fundamentada en una concepción optimista de la posibilidad de alcanzar la paz a partir de la transformación de los conflictos por medios pacíficos (Abella Osorio, 2016).

De acuerdo con Johan Galtung, pionero en los estudios sobre la paz, la visión positiva consiste en la posibilidad de construir una relación armoniosa y sostenible entre actores previamente enemistados. Se alcanza cuando las distintas fracciones en conflicto emprenden proyectos juntos que generan beneficios que son repartidos equitativamente, a pesar de la existencia de marcadas desigualdades entre las partes (Romero-Castillo, 2010).

Dada también la amplitud e integridad de la noción de "paz positiva”, las aproximaciones al concepto de paz desde esta orilla pueden incluir la presencia de la justicia social y el bienestar, la satisfacción de las necesidades básicas y los planes de vida de todas las personas (en sentido espiritual y material), además del ejercicio de la pluralidad cultural, la equidad social y la equidad de género. Igualmente, la visión de paz positiva permite comprenderla no como un fin, sino como un proceso en construcción constante, paralelo a los avances en materia de desarrollo y democracia, y en el cual todos los actores de la sociedad tienen un papel como agentes activos y propositivos (Grasa \& Mateos, 2014).

Otra de las aproximaciones más relevantes a la paz positiva se encuentra en el pensamiento del académico Philip Leech, quien, tomando como referencia el elemento de 
transformación positiva de los conflictos por medios pacíficos, sumado con algunos términos médicos, propone una intervención para los "Estados enfermos de violencia estructural”. Esta incluye una fase de "desacoplamiento", o fomento de la autonomía y el empoderamiento de opresores y oprimidos, para que emprendan proyectos que sean favorables a ambos. Existe otro componente de "reacoplamiento", donde los derechos humanos, la dignidad, la equidad, la solidaridad y la participación reemplazan a la represión y la marginación (Leech, 2014).

Tanto el desacoplamiento como el reacoplamiento están diseñados para garantizar la superación de las antiguas estructuras negativas que legitimaban la desigualdad, la exclusión y la violencia. A cambio se trata de instaurar instituciones modernas, incluyentes y menos violentas. Así mismo, ambos procesos se dirigen a facilitar la reconstrucción de las afectaciones, la reparación de los daños causados a las víctimas de las disputas, la rehabilitación de los servicios y la infraestructura básica, la reestructuración de las sociedades, inclusión de una cultura del entendimiento que propende por la coexistencia pacífica como escenario deseable y sostenible (Leech, 2014)

Colombia, en calidad de receptor de asistencia internacional, percibe la cooperación externa de manera instrumental, puesto que considera que esta debe acompañar, de manera subsidiaria, la construcción de paz en el país, enfocándose en el fortalecimiento de pilares transversales, como el estado social de derecho, la gobernabilidad nacional y local, los DD. HH, la atención integral a las víctimas de la violencia, la promoción de los procesos de verdad, justicia y reparación, y el apoyo y fortalecimiento del Sistema Nacional de Atención y Reparación integral a las Víctimas (Abella Osorio, 2016).

Aunque los vínculos y conexiones entre los fenómenos de cooperación internacional y construcción de paz en Colombia bien pueden parecer explícitos circunstancialmente, desde un punto de vista lógico e histórico, la comprensión de dichos vínculos requiere de una reflexión analítica mucho más precisa. Dicho esto, es pertinente proponer un modelo de comprensión entre la cooperación internacional y la construcción de paz, el cual será descrito en las siguientes líneas.

Se toma como referencia los importantes aportes de la teoría de las relaciones internacionales y se reconoce que la expresión natural del comportamiento externo de los Estados son las relaciones y políticas que se dan en el marco del sistema internacional, sumado a que la consolidación de la paz interna es una responsabilidad fundamentalmente estatal. Sobre esta base, se proponen al realismo clásico y al estructural como puntos de partida útiles para explicar los vínculos entre la cooperación internacional y la construcción de paz en el caso colombiano. Específicamente, y siguiendo las reflexiones de Tokatlian (1999) acerca de la “diplomacia por la paz”, se tomarán las nociones realistas de Mastanduno, Lake e Ikenberry para construir un modelo de comprensión concreto y adaptado a la presente pesquisa.

$\mathrm{Al}$ respecto, combinando operativamente el realismo clásico y el estructural, Mastanduno, Lake e Ikenberry (1989) parten de la idea original de que de todo Estado, sin importar su tamaño, recursos, localización, naturaleza o alcances, tiene la meta última de sobrevivir. Desarrollando esta idea, en el realismo clásico se sostiene que todos los Estados se 
enfrentan en un sistema internacional que es, por fundamento, conflictivo, y por tanto están sometidos a la competencia por el poder, actuando de manera racional unitaria en procura de satisfacer sus respectivos intereses nacionales. Asimismo, los autores mencionados destacan que, en el realismo clásico, se supone que la naturaleza de la política interna es relevante a la hora de entender la proyección externa y las posibilidades reales de éxito de los Estados, conforme con sus mismos objetivos internacionales previamente trazados.

Por otro lado, y tomando como referencia el realismo estructural, Mastanduno, Lake e Ikenberry sustentan que las actividades realizadas por los Estados, en cuanto unidades actuantes en el sistema mundial, se entienden desde el marco de una estructura internacional determinada, cuyo sentido básico, al no exigir una autoridad policial superior, real y legítima, es la anarquía. Teniendo en cuenta lo anterior, una visión desde el realismo estructural situaría el acento de los estudios de la cooperación y la construcción de paz en las transformaciones ocurridas en el seno del sistema internacional, y su impacto correspondiente sobre los comportamientos y manifestaciones de los Estados.

Teniendo en cuenta los elementos indicados, y entendiendo igualmente el concepto de "diplomacia por la paz" como el "[...] manejo deliberado de las relaciones internacionales de un país con el objeto específico de lograr apoyo externo para la resolución de una guerra interna” (Tokatlian, 1999, p. 340). El modelo propuesto además pretende establecer la "diplomacia por la paz" como aquel elemento para entender la conducta internacional de Colombia, y, por tanto, sus alcances y límites a la hora de acoplar los fenómenos de cooperación internacional y construcción de paz nacional. Siguiendo una "diplomacia por la paz" de orden "histórico", se postula aquí que precisamente la evolución de la relación cooperación internacional y construcción de paz en Colombia obedece no solo a una iniciativa liderada por los distintos Gobiernos, sino que los términos "paz" y "desarrollo" han sido empleados como conceptos sombrilla con el fin de clasificar los esfuerzos externos del país por concluir su conflicto armado interno.

Con el fin de facilitar la exposición, el modelo descrito puede ser ilustrado de la siguiente manera (figura 1). 
Figura 1. Modelo de comprensión entre la cooperación internacional y la construcción de paz en Colombia

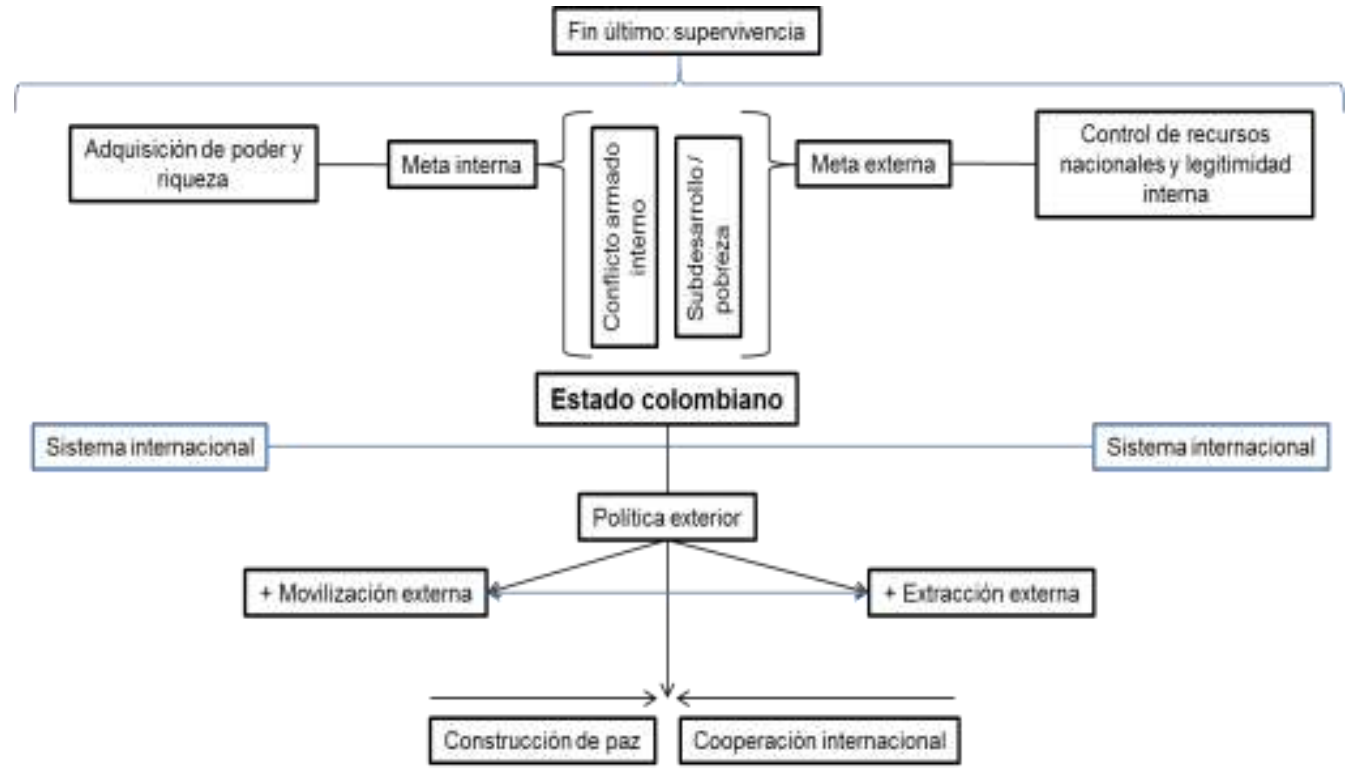

Fuente: elaborado con base en Tokatlian (1999).

En síntesis, el modelo explicativo funcionaria así:

- El Estado colombiano, a lo largo de la historia del conflicto y en el devenir internacional, ha buscado siempre su propia supervivencia. Esto significa que siempre el fin último de su relacionamiento exterior ha apuntado a garantizar este objetivo.

- Tanto en el ámbito interno como en el externo, los distintos Gobiernos han equiparado los medios y fines correspondientes a la resolución del conflicto interno y la superación del subdesarrollo y la pobreza. Esto significa que, históricamente, tanto su meta interna y su meta externa se han dirigido a ambos propósitos, en distintos grados y bajo distintos discursos justificatorios.

- Entendiendo la política exterior colombiana como una exteriorización de su condición e intereses domésticos, esta se ha movido pendularmente entre la movilización externa y la extracción externa, obteniendo distintos resultados a lo largo del tiempo. Llama la atención que, a pesar de sufrir un cruento conflicto armado y ser considerado un factor de riesgo para la seguridad y la estabilidad regional, los Gobiernos han conseguido posicionar al país de forma ventajosa para alcanzar tal movilización y extracción.

- Siguiendo el modelo, los factores de movilización y validación externa sirven el propósito de analizar y evaluar las diversas convergencias y divergencias constituidas entre construcción de paz y cooperación internacional que han sido desarrolladas desde el caso colombiano. Al respecto, el modelo se destaca por facilitar una mirada al contenido, los alcances y las limitaciones de dichas conexiones, permitiendo, a su vez, indicar posibles tendencias factibles de dicha conexión en el mediano y largo plazo.

\section{La cooperación internacional y la construcción de paz: Una reflexión analítica y sistémica de la interdependencia de los fenómenos}

Considerado el Tíbet latinoamericano (Miranda, 2019), en los últimos 20 años Colombia asistió a un claro proceso de internacionalización de su propio conflicto armado interno, que aconteció tanto en los planos político y militar como en la dimensión 
correspondiente a la resolución del conflicto y la construcción de paz. Esto es destacable, puesto que luego de largos años de indecisión, ausencia o presencia marginal de la comunidad internacional frente a los procesos de paz, a partir de 1998 se da un punto de inflexión y se da un creciente involucramiento de los actores internacionales en las iniciativas de negociación en Colombia por medio de distintas modalidades y esquemas de colaboración. La actividad de la comunidad internacional fue intensiva durante las administraciones de Pastrana (1998-2002) y Santos (2010-2018); empero, durante esta última resultó esencial en el desarrollo y logro de un acuerdo de paz histórico con la guerrilla más antigua del continente, las FARC-EP (Barreto, 2014).

La relación entre cooperación internacional y la construcción de paz se erige en un contexto donde se cruzan dos elementos. Primero, hay una tendencia hacia la finalización negociada y no armada de los conflictos armados en el mundo de los últimos 40 años (el $82 \%$ de los conflictos violentos ha cesado por la vía negociada y no por las armas). Segundo, se ha presentado un creciente papel y visibilidad de los terceros actores, provenientes de la comunidad internacional, tanto en la discusión de la agenda global de asuntos prioritarios como en la gestión e incidencia de facilitación y mediación en los proceso de paz resueltos por la vía política (Fisas, 2010).

Históricamente, el nuevo protagonismo de estos actores responde a la fractura del orden de poder internacional como consecuencia de la caída del Muro de Berlín, y la suspensión de los apoyos de las dos superpotencias nucleares a la confrontación bipolar en las guerras civiles en el Tercer Mundo. Esto ha venido a afirmar de manera generalizada una inclinación por parte de terceros involucrarse internacionalmente en procesos de negociación, independientemente de los factores históricos o del contexto ideológico particular que haya marcado la situación de interés (Wallensteen, 2002).

El papel jugado por la comunidad no ha sido el mismo durante los últimos años ni tampoco ha generado siempre los efectos que se proponen los socios en los países de destino. De hecho esta función ha variado. Por un lado, se presentan formas ligeras de intervención como los buenos oficios, en los que terceros Estados y otras organizaciones internacionales, o incluso personas reconocidas por su liderazgo, realizan un acercamiento entre bandos contrarios, buscando promover el inicio o reactivación de los diálogos de paz entre las partes, con miras a conseguir un arreglo pacífico positivo para todos pero sin intervenir directamente en los contenidos de la negociación. También se dan formas más elaboradas y de mayor intervención como la mediación, en la que actores externas ejercen una acción más propositiva, ofreciendo posibles soluciones a la mesa de negociación y generando incentivos, nuevas ideas y opciones para la terminación de un conflicto (Barreto, 2014). También hay maneras intermedias de apoyo internacional como la facilitación y caminos menos directos, pero igualmente relevantes, por ejemplo, una coordinación entre la demanda y la oferta de cooperación del país de destino que se dirija a contribuir a la construcción de paz (que bien ocurre en un sentido más bien posterior).

Ahora bien, no hay duda que cualquier tipo de contribución externa responde a una serie de motivaciones e intereses políticos. Esto se da bien para que terceros actores participen 
tanto en las negociaciones (como mediadores o facilitadores) o como socios en la búsqueda de recursos y ayuda de diversa índole, y pasan igualmente por el crisol del idealismo o el realismo político en las relaciones internacionales.

$\mathrm{Al}$ respecto, es común observar que los aportantes también intentan beneficiarse de los dividendos políticos y económicos de un eventual acuerdo de paz, aprovechándose de la búsqueda por validación y extracción de parte del Estado en la forma de mejores condiciones de orden comercial y en cuanto a la seguridad regional. Ahora bien, en otros casos la evidencia suele ser menos visible y el papel puede limitarse a atender una invitación de las partes en conflicto, aunque igual puede ser percibido como un medio para obtener mayor prestigio y poder $^{3}$ (Barreto, 2014).

Sea mediación, facilitación o aportes por medio de la cooperación internacional, el involucramiento de actores externos contiene varias restricciones, y por eso mismo esto no debe entenderse como un factor necesario y perfecto que lleve a la resolución del conflicto y la construcción de la paz de manera absoluta. La eficacia de un socio externo, sea este una organización o un país amigo, debe ser entendido y analizado siempre por el contexto de las circunstancias de la disputa, así como por la naturaleza del conflicto, las motivaciones (formales y ocultas) de las partes, y su grado de compromiso con la resolución política de la violencia. Empero, el abanico de calidades, capacidades y recursos del mediador también juega un papel importante, siendo unos más preferidos que otros por los observadores internacionales (Bercovitch, 1991).

Concretamente, el acompañamiento internacional en la construcción de paz se puede entender como aquel apoyo que actores de distintas esferas del sistema internacional ofrecen en los procesos de paz (estatales, institucionales o ciudadanos) en un país en tensión, en conflicto armado o en medio de una fase de posconflicto. Este acompañamiento usualmente se implementa por medio de acciones internacionales con las cuales se pretende promover y proteger las iniciativas de paz estatales o ciudadanas ya existentes. Esto contribuye a detener o reducir los grados de violencia destructiva, y genera un cambio social que establezca unas nuevas relaciones constructivas, justas, inclusivas y sostenibles (Barbero, 2006).

En la mayoría de las ocasiones este acompañamiento también toma formas semejantes en los distintos contextos, haciendo uso de mecanismos propios de la cooperación internacional al desarrollo, ayuda humanitaria, la diplomacia, la incidencia política, la protección y la sensibilización desde una mirada de construcción de paz (figura 2). Usualmente, si este tipo de apoyos se mantienen de manera coordinada y convenida en el mediano y largo

\footnotetext{
${ }^{3}$ No solo la mediación, sino también la donación y la oferta de nuevos recursos de cooperación internacional que busca la preeminencia entre ofertantes suelen ser instrumentos para que las grandes potencias internacionales y regionales ejerzan nuevas formas de influencia global, incrementen su capital político y simbólico, y accedan a nuevos campos de influencia al interior de países clave en sus estrategias de inserción y posicionamiento (Touval \& Zartman, 1985). No obstante, las soluciones ofrecidas usualmente no significan la solución integral para finalizar la guerra ni tampoco llegan a convertirse en los contenidos de los acuerdos; más bien, los apoyos tratan de dirimir las incompatibilidades para que las partes en conflicto encuentren por sí solas la vía para la paz (Fisas, 2010).
} 
plazo, pueden robustecer los ánimos y los cambios, allanando el camino hacia una paz justa y sostenible en un país en tensión o guerra (Barbero, 2006).

Figura 2 . Dimensiones del acompañamiento internacional en la construcción de paz

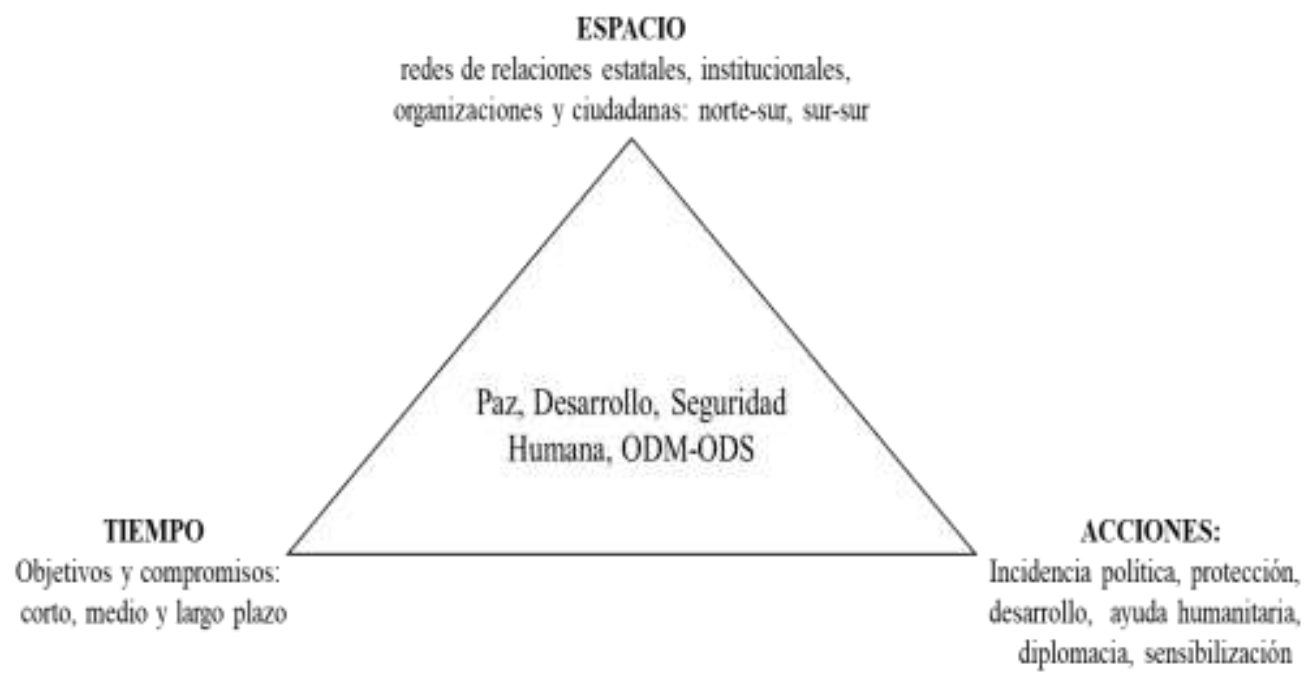

Fuente: elaborado con base en Barbero (2006).

Alejándose de los postulados tradicionalistas de las relaciones internacionales, y, en general, de la política internacional de apreciar las interacciones solo desde un ámbito Estadocéntrico, es importante subrayar que este acompañamiento internacional ha ocurrido y seguirá ocurriendo por medio de caminos diversos, lo que significa que los flujos de intervención y ayuda ocurren y seguirán ocurriendo tanto por medio de actores institucionales (entidades del sistema de Naciones Unidas, la UE, gobiernos de los diferentes países, mesas de donantes, países amigos) como por actores ciudadanos presentes en contextos locales (subnacional, departamental y local). De este último grupo el universo de actores es amplio, y puede llegar a incluir a ONG, municipios, gobiernos departamentales y rurales, sectores académicos, el sector privado, entidades descentralizadas y colectivos solidarios, entre muchos otros.

Los últimos actores no solo son los más numerosos, también desarrollan vínculos y afinidades más cercanas a la sociedad, teniendo al tiempo una cierta mayor independencia frente a los condicionamientos y requisitos políticos y económicos del orden institucional e internacional. Estas características facilitan a estos actores integrarse en modelos no clásicos de cooperación, ahondar en las demandas por corresponsabilidad de los países del norte con los países del sur y su desarrollo, y conformar y mantener redes horizontales y de comunicación entre los ciudadanos de los países vecinos. Estos actores también cuentan con una estructura abierta que les imprime agilidad, flexibilidad, eficacia y experiencia a la hora de entablar nuevas relaciones, actuar en escenarios particulares de orden territorial, gestionar y desarrollar convenios con un mayor enfoque local, e incidir por medio de su activismo en cuestiones concretas a favor de la construcción de la paz. 
En términos generales, se ha visto que los actores internacionales podrán maximizar su apoyo a la paz en países conflictivos, minimizando las externalidades negativas (por ejemplo, ahondando las divisiones ya existentes y agudizando las dinámicas de poder asimétricas y excluyentes) en la medida que ocurra lo siguiente. Por un lado, deben poseer una conciencia más informada frente al nivel de impacto de su actuación en las causas históricas, actuales y potenciales del conflicto objeto de intervención, así como sobre sus propios límites en relación con la naturaleza, intensidad y extensión del conflicto. Por otro lado, tienen que caracterizarse por una mayor independencia y capacidad de análisis del contexto, así como de los intereses y relaciones de todas las partes involucradas y afectadas en el conflicto armado o de tensión (Barbero, 2006).

Según Anderson (1999), las acciones de acompañamiento y apoyo internacional en la construcción de paz tendrán un mayor sentido, pertinencia y eficacia cuando se conjugan los siguientes factores:

i) Los esfuerzos coordinados contribuyen a que las instituciones y las comunidades locales adelanten sus propias iniciativas de paz, atendiendo a sus cosmovisiones y particularidades;

ii) Los procesos de cooperación derivan en la constitución o reforma de instituciones políticas, económicas y culturales dirigidas a prevenir las causas del conflicto;

iii) Las actividades externas incrementan las capacidades de resiliencia de la población vulnerable frente a la violencia o provocaciones que induzcan a la agudización o reactivación de la violencia;

iv) Los aportes redundan en la conformación de plataformas multilaterales que facilitan la protección y sostenibilidad de las iniciativas civiles de paz, así como también del acercamiento permanente entre las partes enfrentadas, $\mathrm{y}$

v) Las interacciones no solo tienen una visión ética, también profundizan en la noción de corresponsabilidad internacional para resolver el conflicto interno.

Tales indicadores de sentido y eficacia del acompañamiento internacional (que además se señalan como condicionamientos para que este genere impactos positivos) se ven restringido por otros factores contextuales y globales.

Entre estos factores se pueden destacar, por ejemplo, el impacto de las decisiones políticas y económicas internacionales (legales e ilegales) en el ámbito territorial estatal, la interdependencia entre los intereses nacionales y los internacionales frente a los conflictos y el tipo de acompañamiento en su resolución, así como la sostenibilidad misma de este tipo de apoyos en el tiempo (Barbero, 2006). Al final, el cruce entre estas condiciones restrictivas, y los factores positivos mencionados por Anderson (1999), permiten distinguir cuatro tipos de incidencia actual y potencialidad de actores internacionales en el acompañamiento de la construcción de paz que son: el acompañamiento puntual, el sostenido, el referencial y por último el protagonista (Barbero, 2006).

Colombia es un caso interesante e ilustrativo a la hora de observar la evolución de los vínculos entre cooperación internacional y construcción de paz, pues es un caso de estudio 
recurrente a la hora de estudiar el acompañamiento internacional en la construcción de paz. En este país, las actividades, esfuerzos y, en general, el grado de involucramiento de distintos actores y esferas internacionales frente a la resolución del conflicto armado interno han sido numerosas y se han venido multiplicando significativamente a partir de los años noventa. Entre los avances de orden operativo más relevantes y concretos en la materia se pueden destacar:

- La conformación temprana de grupos de países amigos que han acompañado a los distintos Gobiernos y la sociedad civil en los procesos de paz con el ELN y las FARC. Mientras que con el proceso de paz del segundo grupo fueron decisivos los apoyos de Noruega, Cuba, Chile y Venezuela; en el proceso ELN se destacó el seguimiento de Suiza, Noruega y España;

- La coordinación estrecha e histórica con el grupo de trabajo del G24 para realizar el seguimiento y monitoreo de los acuerdos que fueron surgiendo de la Mesa de Coordinación y Cooperación Internacional para Colombia;

- El incremento en la diversidad y número de las agencias humanitarias vinculadas al sistema de Naciones Unidas, las cuales se han visto interpeladas a incrementar su ámbito de actuación ante la gravedad de los hechos violentos que había venido registrando el país;

- El mayor protagonismo gradual de la cooperación directa de la UE a partir de diferentes programas de ayuda humanitaria y cooperación al desarrollo. Esto se ve reflejado no solo en la iniciativa estrella "Laboratorios de paz", sino en el apoyo político ${ }^{4}$ del bloque comunitario a instrumentos de justicia transicional como la Ley de Justicia y Paz y la Ley de Víctimas y Restitución de Tierras, y

- El desarrollo planificado y organizado del acompañamiento de la OEA al proceso de verificación de la desmovilización paramilitar, el cual fue financiado y apoyado por diferentes países europeos con el objetivo de contribuir a la construcción de paz adoptando un proceso de DDR.

Estos hitos, sumado al aumento en la cantidad de actores y protagonistas del orden local (municipios, iglesias, redes de comités de solidaridad y alianzas entre ong) enfocados al acompañamiento de las iniciativas estatales y civiles de paz. Esto ha provocado una sinergia interesante en materia cooperación internacional y construcción de paz, lo que constituye un ciclo virtuoso en el que ha ido en aumento no solo la validación y extracción conseguida por el Estado colombiano, también en un incremento en los actores interesados y dispuestos a adelantar alguna incidencia. Entre los motivos que explican estos dos fenómenos se pueden incluir: i) una década propicia para la solidaridad mundial, con un aumento paralelo en los niveles de interrelación producto de la globalización multinivel; ii) una mayor conciencia ciudadana sobre el conflicto armado y social en su complejidad, así como una mayor visibilidad y preocupación producto de su internacionalización; iii) la irrupción y consolidación de un rico y diverso abanico de actividades e iniciativas de la sociedad civil y de las instituciones en favor de la construcción de paz, y iv) la existencia de un importante número de habitantes pertenecientes a la diáspora de refugiados y migrantes colombianos que favorecen la visibilización y el compromiso internacional frente a la situación interna del país.

\footnotetext{
${ }^{4}$ Este apoyo se ha otorgado de manera condicionada al monitoreo de su aplicabilidad, a la transparencia de procesos judiciales y a la reparación real a las víctimas.
} 
Figura 3. Ámbitos de actuación del acompañamiento internacional en la construcción de paz a escala local-municipal

\begin{tabular}{|c|c|c|c|}
\hline \multicolumn{4}{|c|}{ Ámbitos de actuación } \\
\hline $\begin{array}{c}\text { Incidencia } \\
\text { política y } \\
\text { protección }\end{array}$ & Sensibilización & Diplomacia & Desarrollo \\
\hline $\begin{array}{l}\text { 1. Visitas al terreno. } \\
\text { 2. Legitimación: i) } \\
\text { recepción de visitas; } \\
\text { ii) mociones de } \\
\text { apoyo en las } \\
\text { instancias de } \\
\text { gobierno. } \\
\text { 3. Acciones } \\
\text { urgentes en red. } \\
\text { 4. Adhesiones a } \\
\text { manifiestos en red }\end{array}$ & $\begin{array}{l}\text { 1. Fomentar opinión } \\
\text { favorable y motivadora } \\
\text { que facilite: i) } \\
\text { comprensión del } \\
\text { conflicto; y ii) } \\
\text { visibilización de } \\
\text { iniciativas locales y } \\
\text { civiles de paz. } \\
\text { 2. Incorporar tales } \\
\text { iniciativas en campañas y } \\
\text { celebraciones existentes. } \\
\text { 3. Incorporar población } \\
\text { colombiana a nivel } \\
\text { municipal en actividades } \\
\text { y proyectos }\end{array}$ & $\begin{array}{l}\text { 1. Facilitar relaciones } \\
\text { Sur-Sur, Norte-Sur ya } \\
\text { existentes a nivel } \\
\text { municipal. } \\
\text { 2. Fomentar y } \\
\text { robustecer redes de } \\
\text { colaboración entre } \\
\text { municipios. } \\
\text { 3. Facilitar espacios } \\
\text { relacionales de } \\
\text { confianza desde y } \\
\text { hacia los municipios } \\
\text { vecinos, incluyendo } \\
\text { población vulnerable. }\end{array}$ & $\begin{array}{l}\text { Financiamiento articulado y } \\
\text { bilateral de: } \\
\text { 1. Proyectos o programas de } \\
\text { desarrollo. } \\
\text { 2. Proyectos de promoción de } \\
\text { Brigadas Internacionales de } \\
\text { Paz. } \\
\text { 3. Programas de defensores de } \\
\text { derechos humanos con apoyo } \\
\text { de Amnistía Internacional o } \\
\text { similares. } \\
\text { 4. Becas para el fortalecimiento } \\
\text { de iniciativas locales de paz. } \\
\text { 5. Proyectos de intercambio y } \\
\text { constitución de fondos de } \\
\text { emergencia mutuos. }\end{array}$ \\
\hline
\end{tabular}

Fuente: elaborado con base en Delegación de la Unión Europea en Colombia (2011) y Barbero (2006).

Una relación positiva y convergente entre la cooperación internacional y la construcción de paz tiene sentido cuando las estrategias de acompañamiento e intervención logren, primero, visibilizar, reconocer y legitimar a los esfuerzos colombianos, lo que favorecería la apropiación de la resolución de los conflictos y el desarrollo local sostenible. Esta convergencia idealmente contribuiría a reducir los niveles de violencia y destrucción contra la ciudadanía, las organizaciones de base y la memoria colectiva. Segundo, las iniciativas deben facilitar la conformación de contextos relacionales que extiendan el espacio de maniobra para la construcción de paz desde distintos escenarios y no solo desde el político o el militar. Tercero, estas elevan el valor políticos de las iniciativas locales y colabora decididamente en la reconstrucción del tejido social, en un contexto complejo y altamente polarizado como el colombiano. Cuarto, los programas de los socios de hecho deben fortalecen y posibilitan la extensión de prácticas de paz y desarrollo locales que atiendan la superación de las raíces del conflicto. Por último, los apoyos y la cooperación tienen que facilitar la difusión y discusión internacional respecto al contexto del momento y a la realización de denuncias desde fuera del país (Barbero, 2006). 


\section{Conclusiones}

Este artículo pretendió ofrecer una mirada reflexiva y analítica a las dinámicas e intervención de la cooperación internacional en la construcción de paz en Colombia, entendiendo ambos como fenómenos históricos, transversales y dinámicos en la historia nacional. Para conseguir esto se propuso no solo una reflexión desde el contexto de la cooperación, además se buscó analizar las transformaciones y adaptaciones de las dinámicas de ayuda y relación externa del país con el sistema internacional, a la luz de los cambios y demandas internos, generados especialmente a raíz de la ocurrencia y manejo de los fenómenos de subdesarrollo, conflicto y negociación política.

En la primera sección se describió la evolución de la cooperación internacional en Colombia frente al fenómeno de la construcción de paz, destacando los principales hitos históricos. En esta tarea se tuvo en cuenta no solo la evolución de la CI en los ámbitos institucional y social, sino que se prestó especial atención a las conexiones entre los sucesos en el ámbito del sistema internacional y los acontecimientos que marcaron la vida política y económica del país. Al final, el propósito consistía en proponer un diagnóstico amplio dirigido a introducir al lector a la temática, así como para motivar una mirada reflexiva y crítica a lo largo del documento.

En la segunda parte se elaboró el marco teórico-conceptual que se empleó luego con el fin de estudiar el concepto complejo de cooperación internacional. A partir de este, se avanzó hacia una modelo que examinara la relación entre cooperación y construcción de paz, el cual no solo incluyera diferentes elementos históricos de ambas dinámicas, también que funcionara como un marco de estudio útil para realizar análisis prospectivos en esta materia.

A partir de las capacidades, y tambien de los límites de dicho modelo, y teniendo en cuenta el contexto histórico ya expuesto, la tercera sección del artículo se enfocó en analizar reflexivamente la compleja relación entre construcción de paz y CI. El ejercicio anterior permitió entender que entre ambos fenómenos se presenta un vínculo de interdependencia, en el que las ideas y discursos de uno influyen y generan un impacto en el alcance y además imponen ciertas condiciones de los procesos del otro.

Dicho lo anterior, es posible identificar tres conclusiones principales fruto de este análisis. En primer lugar, un análisis sobre paz y cooperación permite observar a Colombia como un caso disruptivo e interesante de estudio, debido a los complejos entrecruzamientos entre ambos fenómenos en el país. Segundo, es posible notar un importante paralelo histórico entre cooperación internacional y construcción de paz, forjando así una relación de interdependencia entre ambos conceptos y fenómenos que ha impactado en la manera en que se desarrollan los procesos de apoyo internacional ante conflictos en diferentes países.

Finalmente, en tercer lugar, el modelo de comprensión aquí propuesto constituye un insumo más en el ejercicio de análisis de estos dos conceptos, el cual se considera de especial utilidad si se tiene en cuenta la estrecha relación y prevalencia en el futuro entre paz y cooperación internacional, además de la importancia de su impacto sobre los destinos de la resolución de conflictos y el desarrollo de los países. 


\section{Referencias}

Abella Osorio, J. D. (2016). La cooperación internacional como instrumento para la construcción de paz en Colombia. Estudio de caso del proyecto "Fortalecimiento institucional para la atención a las víctimas del conflicto (Forvic)" (2009-2014) [tesis de pregrado, Universidad del Rosario]. http://repository.urosario.edu.co/handle/10336/11758

Anderson, M. B. (1999). Do No Harm: How Aid Can Support Peace -Or War. Lynne Rienner Publishers.

Armirola, D. (2017, 8 de septiembre). Senado de Estados Unidos aprobó ayudas para Colombia. El Colombiano. http://www.elcolombiano.com/internacional/senado-de-estadosunidos-aprobo-ayudas-para-colombia-DX7257713

Banchón, M. (2020, 28 de Septiembre). Acaban fondos europeos para la paz en Colombia. ¿Ahora qué? Deutsche Welle. https://www.dw.com/es/acaban-fondos-europeospara-la-paz-en-colombia-ahora-qu\%C3\%A9/a-55428230

Barbero, A. (2006). Construyendo paz en medio de la Guerra: Colombia. Escuela de Cultura de Paz (UAB). http://escolapau.uab.cat/img/programas/colombia/colombiao2oe.pdf

Barreto, M. (2014). Los procesos de paz en Colombia y el rol de la comunidad internacional: ¿crónica de un nacimiento anunciado? RAI - Revista de Análisis Internacional, 5(2), 219-243.

Bercovitch, J. (1991). International mediation. Journal of Peace Research, 28(1), 3-6. https://doi.org/10.1177/0022343391028001002

Calabuig , C., \& Gómez-Torres, M. (2010). La cooperación internacional para el desarrollo. Editorial de la Universitat Politècnica de València.

http://www.upv.es/upl/Uo566378.pdf

Cerdà, T. (2016, 12 de diciembre). Colombia y UE crean el Fondo Fiduciario para el posconflicto. El Espectador. https://www.elespectador.com/noticias/paz/colombia-y-uecrean-el-fondo-fiduciario-el-posconflicto-articulo-670024

Colmenares, D. (2006 ). Cooperación internacional en los procesos de paz del nuevo milenio. Punto de Encuentro, (35), 4-8. http://www.c-r.org/sites/cr.org/files/CR_Cooperacion.pdf

Delegación de la Unión Europea en Colombia. (2011). Segundo laboratorio de paz en Colombia. Principales resultados y aprendizaje. European Union External Action. http://eeas.europa.eu/archives/delegations/colombia/documents/projects/20110909_es.pdf 
Dietrich, W. (2009). La paz: sobre la difícil historia de un concepto clave de la cultura. Universität Innsbruck; Unesco Chair for Peace Studies. http://homepage.univie.ac.at/w.dietrich/php/cms/fileadmin/files/paz.pdf

Duarte, L., \& González, C. (2014). Origen y evolución de la cooperación internacional para el desarrollo. Panorama, 8(15), 117-131. https://doi.org/10.15765/pnrm.v8i15.554

El Espectador. (2016, 4 de febrero). "El nuevo capítulo del Plan Colombia se llamará Paz Colombia”: Obama. El Espectador. https://www.elespectador.com/noticias/politica/elnuevo-capitulo-del-plan-colombia-se-llamara-paz-colo-articulo-614763

El Nuevo Siglo. (2017, 27 de abril). Gobierno creó el Fondo Colombia en Paz. El Nuevo Siglo. http://elnuevosiglo.com.co/articulos/o4-2017-nace-el-fondo-colombia-en-paz

Fernández de Soto, G. (2012, 4 de agosto). Los dos años de Santos en el poder. Avances importantes en política exterior. El Tiempo. http://www.eltiempo.com/Multimedia/especiales/presidencia_juan_m_santos/ARTICULOWEB-NOTA_INTERIOR_MULTIMEDIA-12095228.html

Fisas, V. (2010). Procesos de paz comparados. Cuaderns de Construció de Pa(14), 1-16. Obtenido de http://escolapau.uab.es/img/qcp/procesos_paz_comparados.pdf

González, C., Montoya, D., \& Duarte, L. (2014). Colombia de cara al nuevo regionalismo: renovado: la Alianza del Pacífico. Punto de Vista, 5(9), 137-162. https://doi.org/10.15765/pdv.v5i9.568

Grasa, R., \& Mateos, O. (2014). Guía para trabajar en la construcción de la paz: Qué es y qué supone la construcción de la paz. Kimpres.

Gutiérrez, M. C. (2012). Analizar las relaciones de cooperación entre la Organización de las Naciones Unidas y la Agencia Presidencial para la Acción Social y la Cooperación Internacional [tesis, Universidad del Rosario]. https://repository.urosario.edu.co/handle/10336/2948?show=full

Jiménez , F., \& Aguilar, F. (2014). Una historia de la investigación para la paz. Historia Actual Online HAO, (34), 149-162.

Jiménez, C. (2003). Las teorías de la cooperación internacional dentro de las relaciones internacionales. Polis: Investigación y Análisis Sociopolítico y Psicosocial, 2(3), 115-147.

Keohane, R. (1984). Después de la hegemonía. Grupo Editor Latinoamericano. 
Leech, P. (2014, 14 de julio). Galtung's 'Structural Violence' and the Sierra Leone Civil War c.1985-1992. Transcend Media Service. https://www.transcend.org/tms/2014/o7/galtungs-structural-violence-and-the-sierra-leonecivil-war-c-1985-1992/

Martínez, C., Palomar, R., \& Wilches, J. (2008). Cuarenta años de la institucionalidad de la cooperación internacional en Colombia. Acción Social.

Mastanduno, M., Lake, D. A., \& Ikenberry, G. J. (1989). Towards a Realist Theory of State Action. International Studies Quarterly, 33(4), 457-474. https://doi.org/10.2307/2600522

Miranda, B. (2019, 19 de Julio). Por qué se dice que Colombia es el "Tíbet de Sudamérica" y un "país parroquial" (y qué ha cambiado en los últimos años). $B B C$. https://www.bbc.com/mundo/noticias-america-latina-49042052

Monroy, J. C. (2012, 13 de septiembre). Conflicto costó \$207 billones en 10 años. El Colombiano. https://www.elcolombiano.com/amp/historico/conflicto_costo_207_billones_en_10_anos-KFEC_206840

Muñoz, F., \& López, M. (2000). Historia de la Paz. Universidad de Granada.

Pedraza, J., \& Duarte, L. (2016). La relación política exterior y cooperación internacional. El caso de Colombia 2002-2015. VIII Congreso de Relaciones Internacionales, 131. http://sedici.unlp.edu.ar/bitstream/handle/10915/58218/Documento_completo.pdfPDFA.pdf?sequence $=1$

Presidencia de la República de Colombia. (2017, 14 de febrero). Colombia en Paz, un Fondo de Fondos para llegar a los territorios afectados por el conflicto. http://www.posconflicto.gov.co/sala-prensa/noticias/2017/Paginas/20170214-Colombia-enPaz-un-Fondo-de-Fondos-para-llegar-a-los-territorios-afectados-por-el-conflicto.aspx

Revista Semana. (2016, 2 de abril). Un millonario ofrecimiento de Estados Unidos para la paz de Colombia. Revista Semana. http://www.semana.com/nacion/articulo/plancolombia-barack-obama-y-juan-manuel-santos-celebran-la-nueva-fase/459323

Rolón Salazar, M. (2018, 26 de diciembre). Hay más víctimas de desplazamiento forzado en Colombia que número de habitantes en Costa Rica”. Oficina del Alto Comisionado de las Naciones Unidas para los Refugiados. https://www.acnur.org/noticias/noticia/2018/12/5c243ef94/hay-mas-victimas-dedesplazamiento-forzado-en-colombia-que-numero-de-habitantes.html

Romero-Castillo, E. (2010, 20 de septiembre). Johan Galtung: Me impresiona la idea de unos Estados Unidos de Latinoamérica. Deutsche Welle. http://www.dw.com/es/johangaltung-me-impresiona-la-idea-de-unos-estados-unidos-de-latinoam \% 3 \%A9rica/a-6021716 
Sanahuja, J. (2001). Cooperación al desarrollo y globalización: Entre la beneficencia pública internacional y el Estado del bienestar mundial. Ponencia CIDEAL, 71-102.

Sikkink, K., Marchesi, B., Dixon, P., \& D’Alessandra, F. (2014, 24 de octubre). Reparaciones Integrales en Colombia: Logros y Desafíos. Evaluación Comparativa y Global. http://static.iris.net.co/semana/upload/documents/Documento_409315_20141116.pdf

Tickner, A. (1997). Hacia un modelo normativo del consenso en las instituciones internacionales. Colombia Internacional, (45), 3-11. https://doi.org/10.7440/colombiaint38.1997.00.

Tokatlian, J. G. (1999). Colombia en guerra: las diplomacias por la paz. Desarrollo Económico, 39(155), 339-360. https://doi.org/10.2307/3455949 Westview.

Touval, S., \& Zartman, W. (1985). International Mediation in Theory and Practice.

Villa, E., Restrepo, J. A., \& Moscoso, M. (2013). Crecimiento económico, conflicto armado y crimen. Vniversitas Económica, 1-26.

http://cerac.org.co/assets/pdf/Crecimiento_Confl-icto_Armado_y_Crimen_Organizado-JAREV-MM.pdf

Wallensteen, P. (2002). Understanding conflict resolution: war, peace and the global system. Sage Publications. 